\title{
Pneumocephalus following treatment of Esthesioneuroblastoma
}

\author{
E.H. Klimek, R.L. Macdonald and J.H.N.Deck
}

\begin{abstract}
The course of a patient with an olfactory neuroblastoma treated with conventional doses of chemotherapeutic agents and radiotherapy is presented. The patient survived 34 months after tumour necrosis with resultant pneumocephalus requiring surgical intervention.
\end{abstract}

RÉSUMÉ: Pneumo-encéphale suite ay traitement d'un esthésioneuroblastome. Nous rapportons l'évolution d'un patient présentant un neuroblastome olfactif traité par des doses conventionnelles de chimiothérapie et de radiothérapie. Le patient a survécu 34 mois après la nécrose de la tumeur qui a occasionné un pneumo-encéphale nécessitant un traitement chirurgical.

Can. J. Neurol. Sci. 199I; 18: 358-360

Esthesioneuroblastoma, or olfactory neuroblastoma, is a malignant neuroblastic tumour thought to arise from the olfactory epithelium of the nasal cavity. 1,2 The tumour is sufficiently rare that many reports in the literature are either small series ${ }^{3-6}$ or isolated cases with reviews of the literature..$^{7-9}$ This case report adds to this body of information by summarizing the course of an infrequently diagnosed illness and illustrating a previously unrecognized complication after treatment.

\section{CASE REPORT}

A 64-year-old man presented in May 1987 complaining of progressive left eye pain and periorbital swelling over a six month period. Further questioning revealed a 4 year history of anosmia with frequent episodes of epistaxis from the left nares. The previous medical history was unremarkable. The patient was a retired aircraft maintenance man and smoked approximately $1 / 2$ pack per day for 22 years.

Physical examination revealed restricted movement of the left eye causing mild diplopia in all directions. Evident proptosis of the left eye with chemosis was noted and a $1 \mathrm{~cm}$ mass in the left medial canthus was palpable. No cervical lymphadenopathy was palpable. The chest $x-$ ray was unremarkable. A computed tomographic (CT) scan of the head demonstrated an extensive mass involving the cribriform plate with bone destruction, abutting the orbit and invading both frontal lobes of the brain. A magnetic resonance image (MRI) scan (Signa, General Electric Medical Systems, Milwaukee, Wisconsin) was obtained to further delineate the mass (see Figure 1). The tumour bridged the cribriform plate and involved the brain and sinuses (Kadish stage $\mathrm{C}^{10}$ ). Transnasal biopsy revealed the tumour to be an olfactory neuroblastoma.

Treatment was instituted in July 1987 with Dexamethasone $10 \mathrm{nmg}$ intravenously (IV), Cyclophosphamide $1,800 \mathrm{mg}(1 \mathrm{G} / \mathrm{m}) \mathrm{IV}$,
Adriamcycin $90 \mathrm{nmg}(50 \mathrm{mg} / \mathrm{m} 2)$ IV and Vincristine $2 \mathrm{mg} \mathrm{IV}$. This regimen was repeated two weeks later and a follow up MRI scan showed no alteration of tumour morphology. The patient then received radiotherapy consisting of 5,000 centiGray (tumour dose) in 25 fractions over 6 weeks with shielding of the eyes and uninvolved brain.

In October 1987, within two weeks of the last radiotherapy, the patient presented with subacute progressive confusion. An MRI scan was obtained (Figures 2 and 3 ) revealing extensive tissue destruction and pneumocephaly. A fistulous tract extending from the nasopharynx through necrotic tissue into the right frontal lobe was found at surgery.

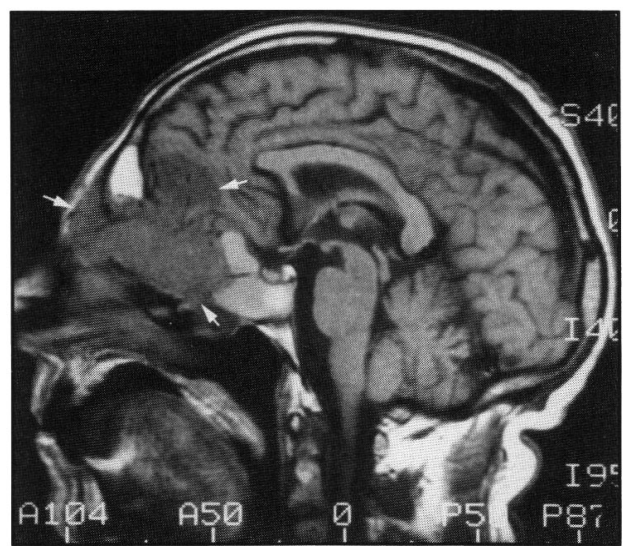

Figure I-MRI scan TI weighted image, sagittal section through midline revealing tumour (outlined by arrows) crossing cribriform plate extending into anterior fossa.

From the Department of Medicine, Women's College Hospital, Department of Radiology, Toronto Hospital Corporation (Western Division (E.H.K.); the Division of Neurosurgery, University of Toronto (R.L.M.); the Division of Neuropathology, Toronto Hospital Corporation (General Division (J.H.N.D.)

Received: December 17, 1990. Accepted January 4, 1991

Reprint requests to: E. Klimek, MD, Women's College Hospital, 76 Grenville Street, Toronto, Ontario, Canada M5S 1B2 
Histologic examination of the resected tumour (see Figure 4) revealed a highly cellular mass composed of small cells with dense nuclei superimposed on a fine fibrillar matrix. The cells possess little cytoplasm and showed minimal pleomorphism. No mitoses were seen and definite rosette formation was not appreciated. The nests and cords of tumour cells were separated by irregular septae of fibrous tissue. Extensive areas of necrosis were seen. Immunohistochemical stains for glial fibrillary acidic protein (GFAP), cytokeratin (CK), human common leukocyte antigen (HLA) and neurofilament (NF) were negative. Neuron specific enolase (NSE) was positive and occasional cells showed positivity for S-100 protein. 11 Ultrastructural analysis of the tumour was not obtained. The pathologic diagnosis was olfactory neuroblastoma.

The patient was discharged for convalescence into the care of his family physician. His postoperative mental state showed marked memory impairment and personality change. Over the ensuing 34 months progressive bilateral cervical lymphadenopathy reached "grapefruit size" and the patient succumbed with respiratory complications of upper airway obstruction in August of 1990 . No further investigations or autopsy had been performed.

\section{Discussion}

Olfactory neuroblastoma is a neuroepithelial-cell-derived neoplasm of the olfactory mucosa composed of homogeneous small round cells which contain neurosecretory granules. The histologic homogeneity contrasts with case reports which demonstrate speckled calcification throughout on CT examination, 12,13 ganglioneuroblastic transformation following subtotal resection and radiotherapy, ${ }^{14}$ and dual differentiation of the tumour into melanoma and esthesioneuroblastoma after transplantation into mice. ${ }^{15}$ The natural history and optimal treatment of olfactory neuroblastoma is not well defined. $16 \mathrm{~A}$ review of reported cases by Elkon et al. suggests that the three year survival correlates with staging and varies from $52.9-88.9 \%$ when surgical and radiation therapy are administered. ${ }^{3}$ Combined treatment with local resection and radiation in disease spread to the adjacent paranasal sinuses (Kadish stage B) resulted in local tumour recurrence in 2 out of 7 patients. ${ }^{17}$ Patients with tumour presenting extending beyond the nasal cavity and sinuses presently receive radiation therapy of 6,000-6,500 centiGray in 7 weeks.

Chemotherapy has been suggested as palliative therapy and may have a beneficial effect on olfactory neuroblastoma in approximately $62 \%$ of patients when combined with other treat-

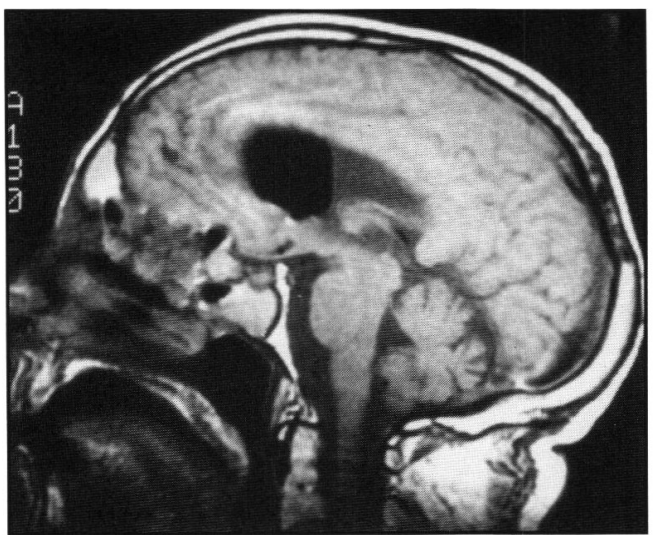

Figure $2-M R I$ scan Tl weighted image, sagittal section near midline revealing air-fluid level in third ventricle and air pockets in tissues near nasopharynx. ment modalities. ${ }^{18}$ Combination chemotherapy with cyclophosphamide $\left(150 \mathrm{mg} / \mathrm{m} 2\right.$ daily for 7 days), doxorubicin $\left(35 \mathrm{mg} / \mathrm{m}^{2}\right)$ and vincristine $\left(1 \mathrm{mg} / \mathrm{m}^{2}\right)$ has previously been administered with radiation therapy..$^{19}$ Four of five patients with Kadish stage $\mathrm{C}$ olfactory neuroblastoma either died (3) or still had residual tumour (1) after treatment with supralethal high dose chemotherapy followed by cryopreserved autologous bone marrow transplantation. ${ }^{20}$ The remaining patient was alive with no tumour evident eighteen months after transplantation.

Spontaneous pneumocephaly has been described following treatment of nasopharyngeal carcinoma, ${ }^{21}$ nasal polypectomy ${ }^{22}$ and radiation therapy of pituitary adenoma. ${ }^{23}$ Pneumocephalus

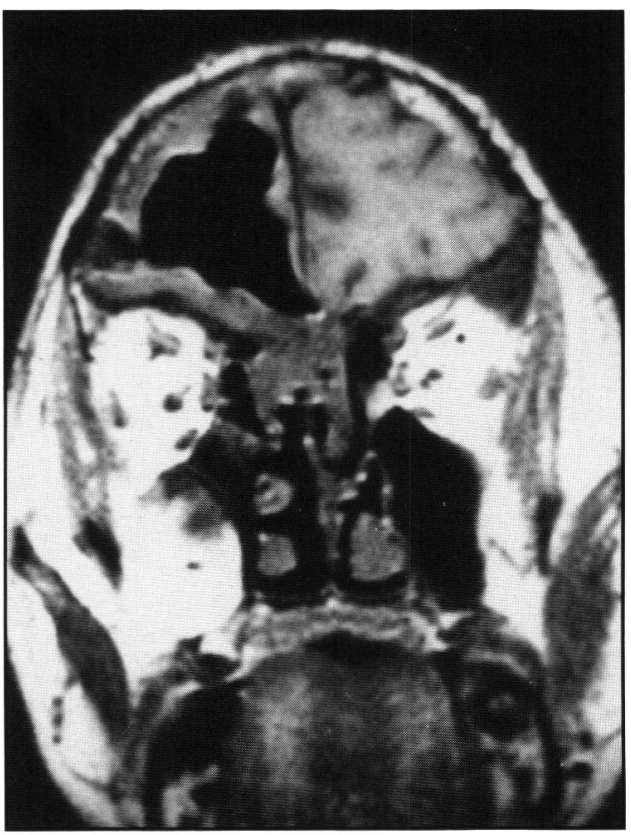

Figure 3-MRI scan $T I$ weighted image, coronal section through anterior fossa revealing extensive right frontal tissue loss and pneumocranium.

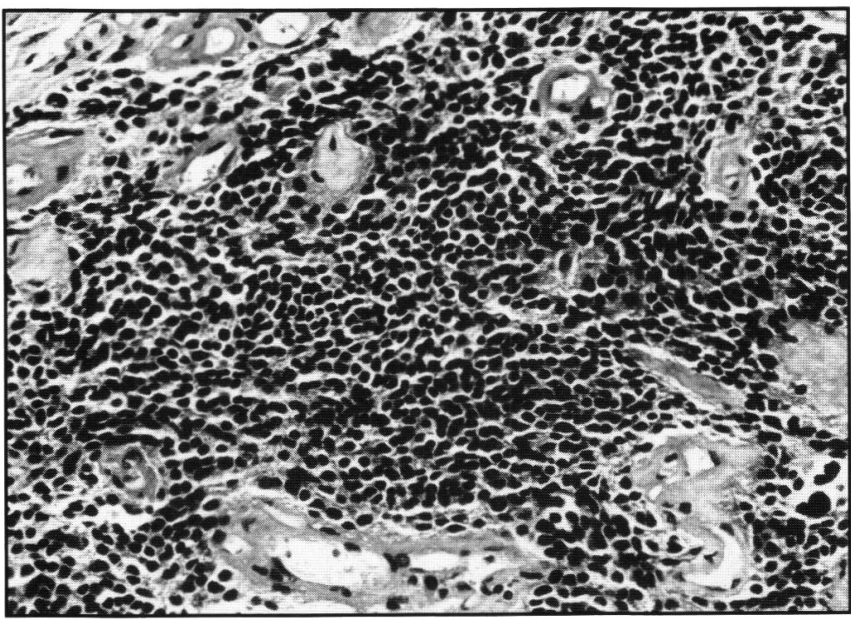

Figure 4-Photomicrograph of the neoplasm showing small nondescript cells interspersed between fibrovascular connective tissue septae (hematoxylin and eosin X 250). 
may result from cranial trauma, gas forming infection of the paranasal sinuses or intracranial cavity or consequent to surgical opening of the dura. Spontaneous pneumocephalus in the absence of predisposing factors is usually thought to occur through congenital bony and dural defects of the skull.24 The intracranial air can be localized to any of the extradural, subdural, subarachnoid intraparenchymal or intraventricular spaces. In the present case a fistulous tract through necrotic tissue allowed communication of the ventricular system with the nasal cavity.

\section{REFERENCES}

1. Axe S, Kuhajda FP. Esthesioneuroblastoma; Intermediate filaments, neuroendocrine and tissue specific antigens. Am J Clin Patho 1987; 88: 2: 139-145.

2. Silva EG, Butler JJ, MacKay B, et al. Neuroblastomas and endocrine carcinomas of the nasal cavity. A proposed new classification. Cancer 1982; 50: 2388-2405.

3. Elkon D, Hightower SI, Lim, et al. Esthesioneuroblastoma. Cancer 1979; 44: 1087-1094.

4. Bailey BJ, Barton S. Olfactory neuroblastoma: Management and Prognosis. Arch Otolaryngol 1975; 101: 1-5.

5. Cantrell RW, Ghoryeb BY, Fitz-hugh GS. Esthesioneuroblastoma: Diagnosis and Treatment. Ann Otol 1977: 86: 760-765.

6. Shah JP, Feghali J. Esthesioneuroblastoma. Am J Surg 1981; 142: 456-458.

7. Schroth G, Gawehn J, Marquardt B, et al. Case report: MR imaging of esthesioneuroblastoma. J Comput Assist Tomogr 1986; 10: 316-319.

8. Cullen MJ, Cusack DA, O'Briain DS, et al. Neurosecretion of arginine vasopressin by an olfactory neuroblastoma causing reversible syndrome of antidiuresis. Am J Med 1986; 81: 911916.

9. Anavi $\mathrm{Y}$, Bahar $\mathrm{M}$, Ben-Bassat $\mathrm{M}$. Olfactory Neuroblastoma: Repon of a case and review of the literature. J Oral Maxillofacial Surg 1989; 47: 5: 514-517.

10. Kadish S, Goodman M, Wang CC. Olfactory Neuroblastoma. A clinical analysis of 17 cases. Cancer 1976: 37: 1571-1576.

11. Mills S, Fechner RE. "Undifferentiated" neoplasms of the sinonasal region: Differential diagnosis based on clinical, light microscopic, immunohistochemical, and ultrastructural features. Seminars in Diagn Pathol 1989; 6: 4: 316-328.

12. Proceedings of the Tumour Board of the Children's Hospital of Philadelphia: Esthesioneuroblastoma. Med and Ped Oncol 1989; 17: 433-438.

13. Hurst RW, Erickson S, Cail WS, et al. Computed tomographic features of esthesioneuroblastoma. Neuroradiology 1989; 31: 253257.

14. Chan JKC, Lau WH, Yuen RWS. Brief report: Ganglioneuroblastic transformation of olfactory neuroblastoma. Histopathology 1989; 14: 4: 425-428.

15. Llombart-Bosch A, Carda C, Peydro-Olaya A, et al. Pigmented esthesioneuroblastoma showing dual differentiation following transplantation in nude mice. Virchows Archive A Pathol Anat 1989; 41: 199-208.

16. Wade PM, Smith RE, Johns ME. Response of esthesioneuroblastoma to chemotherapy: report of five cases and review of the literature. Cancer 1984; 53: 1036-1041.

17. O'Connor TA, McLean P, Juillard JR, et al. Olfactory neuroblastoma. Cancer 1989; 63: 2426-2428.

18. Mohanti BK, Rath BK, Baser B, et al. Recurrent olfactory neuroblastoma treated by radiation, surgery and chemotherapy: a case report. J Surg Oncol 1987; 34: 22-26.

19. Walters TR, Pushparaj N, Ghander AZ. Olfactory neuroblastoma response to combination chemotherapy. Arch Otolaryngol 1980; 106: $242-243$.

20. Stewart FM, Lazarus HM, Levine PA, et al. High-dose chemotherapy and autologous marrow transplantation for esthesioneuroblastoma and sinonasal undifferentiated carcinoma. Am J Clin Oncol 1989; 12: 3: 217-221.

21. Isler RJ, Weber AL. Pneumocephalus from paranasal sinus carcinoma. Annal Otol. 1978; 87: 142-143.

22. Osboume JE, Parker AJ. Air in the ventricles: an unusual complication of nasal polypectomy. J Laryngol Otol 1985; 99: 12751278.

23. David HJ, Fredie G, Parker WJ. Spontaneous pneumoventriculogram following radiation of a pituitary adenoma. Neurology $1975 ; 25: 888-890$.

24. Pop PM, Thomson DE, Zinke AN, et al. Tension Pneumocephalus. J Comput Assist Tomogr 1982; 6: 894-901. 